\title{
Albizia Benth Oil Maleinised Polyesteramides: Synthesis, Structure, and Characteristics
}

\author{
C. O. Akintayo, E. T. Akintayo, and M. A. Azeez \\ Department of Chemistry, University of Ado Ekiti, Ado-Ekiti 4418, Nigeria \\ Correspondence should be addressed to C. O. Akintayo, fkintayo@yahoo.co.uk
}

Received 18 January 2012; Accepted 14 February 2012

Academic Editors: A. Buzarovska and X. Zheng

Copyright () 2012 C. O. Akintayo et al. This is an open access article distributed under the Creative Commons Attribution License, which permits unrestricted use, distribution, and reproduction in any medium, provided the original work is properly cited.

\begin{abstract}
Albizia benth oil (ABO) has been employed in the preparation of polyesteramide resin via the condensation of hydroxyethylamide derivatives of $\mathrm{ABO}$ fatty acids and phthalic anhydride. The maleinised Albizia benth oil polyesteramide was prepared, using maleinised hydroxyethylamide derivatives of $\mathrm{ABO}$ obtained by appending maleate half esters onto the hydroxyethylamide derivative of $\mathrm{ABO}$ and phthalic anhydride. Structural elucidation and characterisation of the products carried out revealed that maleic anhydride can successfully be used to modify polyesteramides, to improve its properties such as drying, flexibility, scratch hardness, impact resistance, chemical resistance, and lower curing temperature.
\end{abstract}

\section{Introduction}

Current interest in cheap and biodegradable polymeric materials has given impetus to the development of materials from readily available, renewable, inexpensive, and natural resources [1]. This interest is justified by the environmental advantages of these substances; zero net carbon and biodegradability. These polymeres also constitute a new outlet for vegetable products [2].

In Nigeria, vegetable oil-dependent industries rely mostly on imported oils; oils such as linseed and soybean are very expensive. However, $\mathrm{ABO}$ is an agricultural byproduct, abundantly available in the country. It holds considerable promise as a source of unsaturated oil and suitable for the production of industrial chemical feedstocks.

A class of alkyd-resins polymers from $\mathrm{ABO}$ have earlier been prepared $[3,4]$. Just like other commercially viable polymers are currently being investigated. This research is aimed at synthesizing, characterising and evaluating $\mathrm{ABO}$ polyesteramide, modified by maleinisation for improved film characteristics over the conventional alkyds. It is part of the ongoing investigation on the preparation of new polymeric materials from $\mathrm{ABO}$. Results of possible application of Albizia benth seed oil outlined in this research could trigger an expansion albizia plant cultivation, a development that will improve income of peasant farmers. Similarly, many industries will have cheaper raw materials to use, leading to inexpensive consumer items. Environmental friendly and boidegradable polymers, produced from the biobased chemical feedstock, will promote a cleaner environment.

\section{Experimental}

2.1. Collection of Samples. Albizia benth seeds were collected from nearby farms and bushes in Ado Ekiti, Nigeria. The seeds were milled on a C\&N Junior Laboratory mill size 5 (Christy and Norris Limited Engineers, Chemlsford, UK).

2.2. Extraction and Refining of Oil. Albizia benth oil (ABO) was extracted using $n$-hexane in a soxhlet apparatus and solvent removed on a rotavapour. The crude oils were refined by agitating with $18 \mathrm{M} \mathrm{NaOH}(1: 30 \mathrm{~g} / \mathrm{g})$ for $15 \mathrm{~min}$. The resultant mixture was then heated to $75-80^{\circ} \mathrm{C}$ to break the soap stock. The neutral oil was separated by centrifugation.

\subsection{Synthesis of Oil Derivatives}

2.3.1. Synthesis of Hydroxylethyl Albizia Benth Oil Fatty Amide. $0.32 \mathrm{~mol}$ of diethanolamine and $0.007 \mathrm{~mol}$ of sodium methoxide were mixed in a four-necked round bottom 


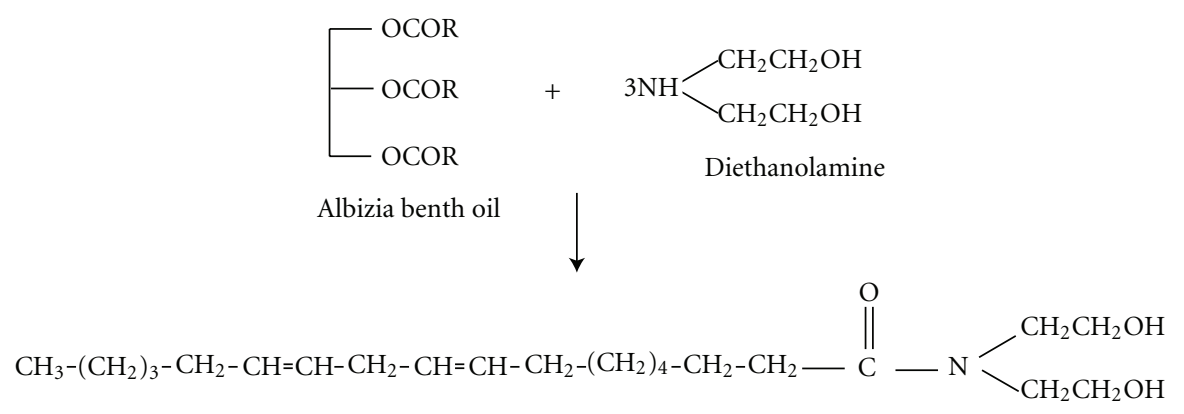

Hydroxylethyl albizia benth oil amide (HEABOA)

SCHeme 1

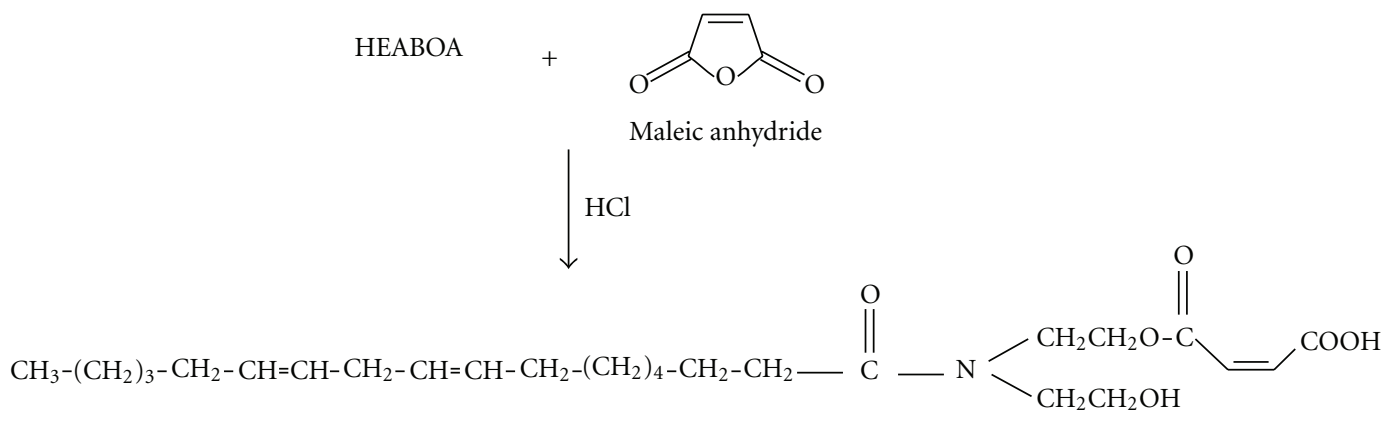

Maleinised hydroxylethyl albizia benthoil amide (MA-HEABOA)

Scheme 2

flask fitted with an electrical stirrer, thermometer, and condenser and contents heated to $110^{\circ} \mathrm{C}$ while stirring.

$\mathrm{ABO}(0.1 \mathrm{~mol})$ was then added dropwisely over a period of $60 \mathrm{~min}$. Progress of the reaction was monitored by TLC. On completion the reaction product was dissolved in diethyl ether, washed with $15 \% \mathrm{NaCl}$, and dried over $\mathrm{Na}_{2} \mathrm{SO}_{4}$. The ethereal layer was filtered and evaporated in a vacuum evaporator to obtain the bis (2-hydroxyethyl) Albizia benth oil fatty amide (HEABOA).

2.3.2. Synthesis of Maleinised Polyesteramide. $10 \mathrm{~g}$ of HEABOA prepared above was dissolved in $50 \mathrm{~mL}$ xylene: acetone mixture $(3: 1)$ in a four-necked flask fitted with nitrogen inlet gas, and mechanically stirrered. The temperature of the system was brought to $100^{\circ} \mathrm{C}$. Four drops of $1 \mathrm{~N} \mathrm{HCl}$ were added to the mixture and $1.5 \mathrm{~g}$ of maleic anhydride dissolved in xylene:acetone $(3: 1)$ added dropwisely. The temperature of the reacting medium was raised to $145^{\circ} \mathrm{C}$ and reaction allowed to continue for $4 \mathrm{~h}$ to obtain the maleinised hydroxylethyl Albizia benth oil fatty amide (MA-HEABOA). $2.5 \mathrm{~g}$ of phthalic anhydride was added to the resulting product and the reaction allowed to continue for $6 \mathrm{~h}$ when acid value determination indicated complete reaction. Excess solvent was removed over rotary evaporatour.
2.4. Characterisation. Samples were characterised by spectroscopic techniques such as FT-IR, ${ }^{1} \mathrm{H}$ NMR, and ${ }^{13} \mathrm{C}$ NMR. FTIR spectra were recorded on Tensor 27 FTIR-H1026302 (Bruker Optik, GmbH, Germany) and ${ }^{1} \mathrm{H}$ and ${ }^{13} \mathrm{C}-\mathrm{NMR}$ spectra obtained on a Bruker Avance-400 (Bruker Instruments, Inc. Karlsruhe, Germany) Fourier transform spectrometer operating at $400.6 \mathrm{MHz}$. The gated decoupling pulse sequence was used with the following parameters: number of scans, 256; acquisition time, $1.366 \mathrm{~s}$; pulse width $10.3 \mu \mathrm{s}$. Free induction decay FID was transformed and zero filled to $300 \mathrm{~K}$ to give digital resolution of $2 \mathrm{~Hz} /$ point. Thermal analysis was carried out by DSC $822^{\mathrm{e}}$ (Mettler Toledo $\mathrm{GmBH}$, Giessen, Germany). Hydroxyl value (HV), Iodine value (IV), saponification value (SV), and refractive index (RI) were determined according to standard procedures [5].

For DSC analysis, approximately $10 \mathrm{mg}$ of the resin sample was weighed into aluminium pans hermetically sealed into place. The sealed sample was initially kept at $30^{\circ} \mathrm{C}$ for 5 minutes and then heated to $250^{\circ} \mathrm{C}$ to erase its thermal history. To record the crystallization curve, the sample was cooled to $-100^{\circ} \mathrm{C}$ and kept at the temperature for 5 minutes, after which the sample was heated to $250^{\circ} \mathrm{C}$. Nitrogen was used for the cooling while both heating and cooling were done at the rate of $10^{\circ} \mathrm{C} / \mathrm{min}$. 


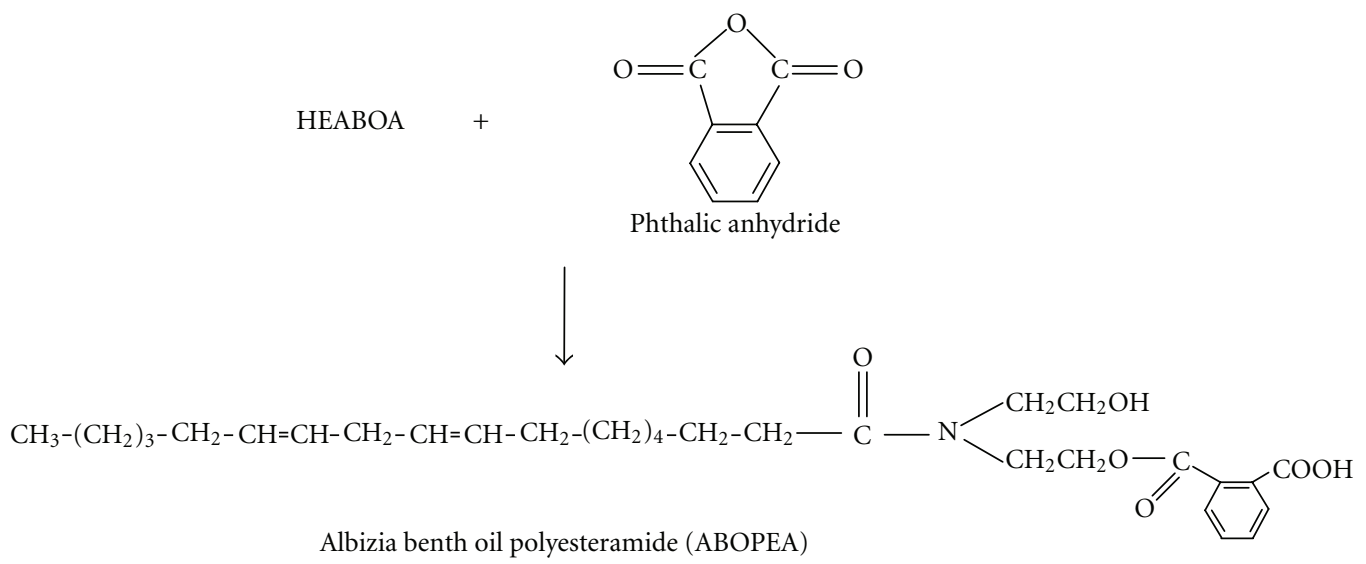

Scheme 3

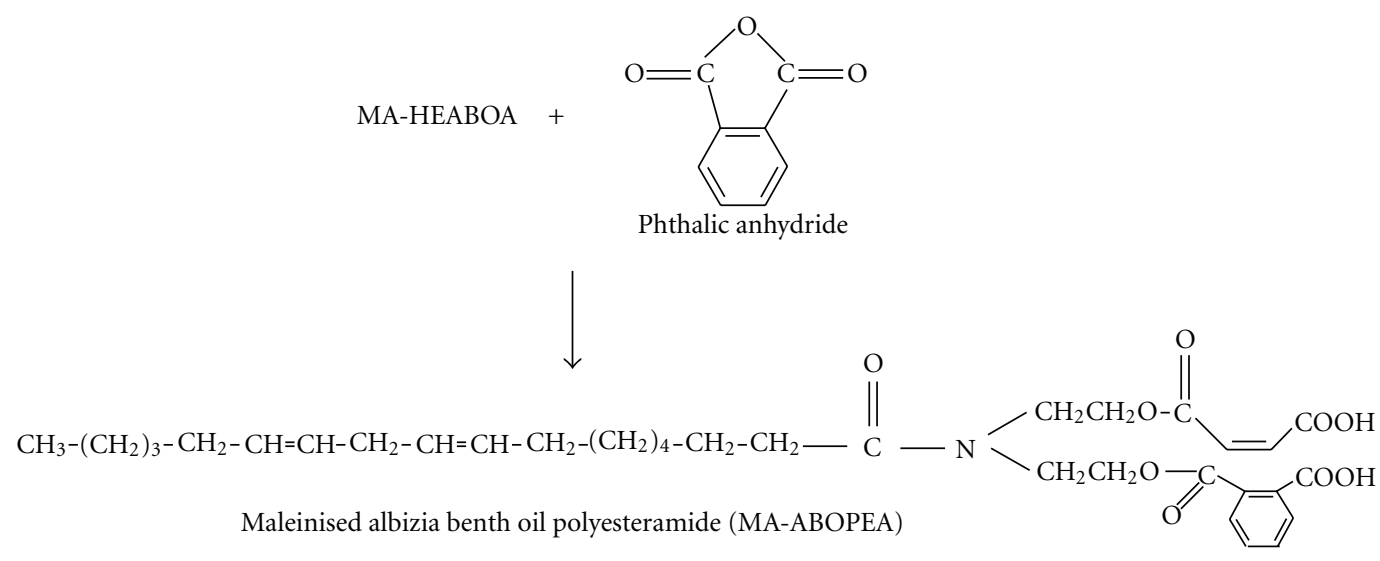

SCHeme 4

2.5. Evaluation of Physicomechanical Characteristics. Samples were thinned in toluene to a brushable consistency. The solutions prepared were applied by brush on clean mild steel panels of $15 \mathrm{~cm} \times 15 \mathrm{~cm}$ for evaluating drying time, tin panels of the size $15 \times 15 \mathrm{~cm}$ for flexibility and adhesion, scratch hardness and impact resistance and glass panels of the size $15 \times 15 \mathrm{~cm}$ for water, alkali, and solvent resistance. All coated panels were air dried for $48 \mathrm{hr}$ and sides protected by dipping them into molten wax before carrying out the above tests. The film characteristics were determined according to Indian standard specifications [6].

\section{Results and Discussion}

The reaction schemes for the preparation of the hydroxylethyl Albizia benth oil amide (HEABOA), the maleinised HEABOA, Albizia benth oil polyesteramide (ABOPEA) and the maleinised ABOPEA are outlined in Schemes 1, 2, 3, and 4 respectively. The confirmation of the structures was carried out by FT-IR and NMR spectroscopic studies.

FT-IR spectrum of HEABOA (Figure 1) shows the characteristic absorption band at $3400 \mathrm{~cm}^{-1}$ for alcoholic $\mathrm{OH}$. Asymmetric and symmetric $\mathrm{CH}_{2}$-absorption bands appear at 2925 and $2854 \mathrm{~cm}^{-1}$ respectively. The amide carbonyl peak is observed at $1621 \mathrm{~cm}^{-1}$. The $-\mathrm{CH}_{2}$ bending is at $1466 \mathrm{~cm}^{-1}$. The $\mathrm{C}=\mathrm{C}$ stretching band appear at $3008 \mathrm{~cm}^{-1}$ and the $\mathrm{OH}$ deformation is at $1049 \mathrm{~cm}^{-1}$. In the FTIR of the MA$\mathrm{HEABOA}$, there is considerable reduction in the alcoholic $\mathrm{OH}$ band appearing at $3403 \mathrm{~cm}^{-1}$ compared to that observed in the HEABOA indicating that some of the hydroxyl groups may have reacted. The reaction of the maleic anhydride at the $\mathrm{OH}$ site is corroborated by the fact that the $\mathrm{HC}=\mathrm{CH}$ at $3008 \mathrm{~cm}^{-1}$ also appears in the FTIR of MA-HEABOA indicating that unsaturation was preserved during the maleinization reaction. The MA-HEABOA spectrum further shows the new ester and carboxylic acid carbonyl overlapping at $1735 \mathrm{~cm}^{-1}$ causing a broadening of the peak. The carbonyl of the amide appears at $1624 \mathrm{~cm}^{-1}$. The $\mathrm{C}-\mathrm{O}-\mathrm{C}$ ester stretching vibration appears at $1165 \mathrm{~cm}^{-1}$ and $\mathrm{OH}$ bending at $1073 \mathrm{~cm}^{-1}$.

FTIR of the ABOPEA (Figure 2) presents peaks at 3009, 2925 , and $2854 \mathrm{~cm}^{-1}$ assigned to the $\mathrm{HC}=\mathrm{CH}, \mathrm{CH}_{2}$ asymmetric, and $\mathrm{CH}_{2}$ symmetric stretching respectively. The amide and ester carbonyls appear at 1613 and $1731 \mathrm{~cm}^{-1}$, respectively, and the $\mathrm{C}-\mathrm{O}-\mathrm{C}$ asymmetric band appears at $1282 \mathrm{~cm}^{-1}$. The $\mathrm{C}-\mathrm{O}$ stretching vibration is observed at 


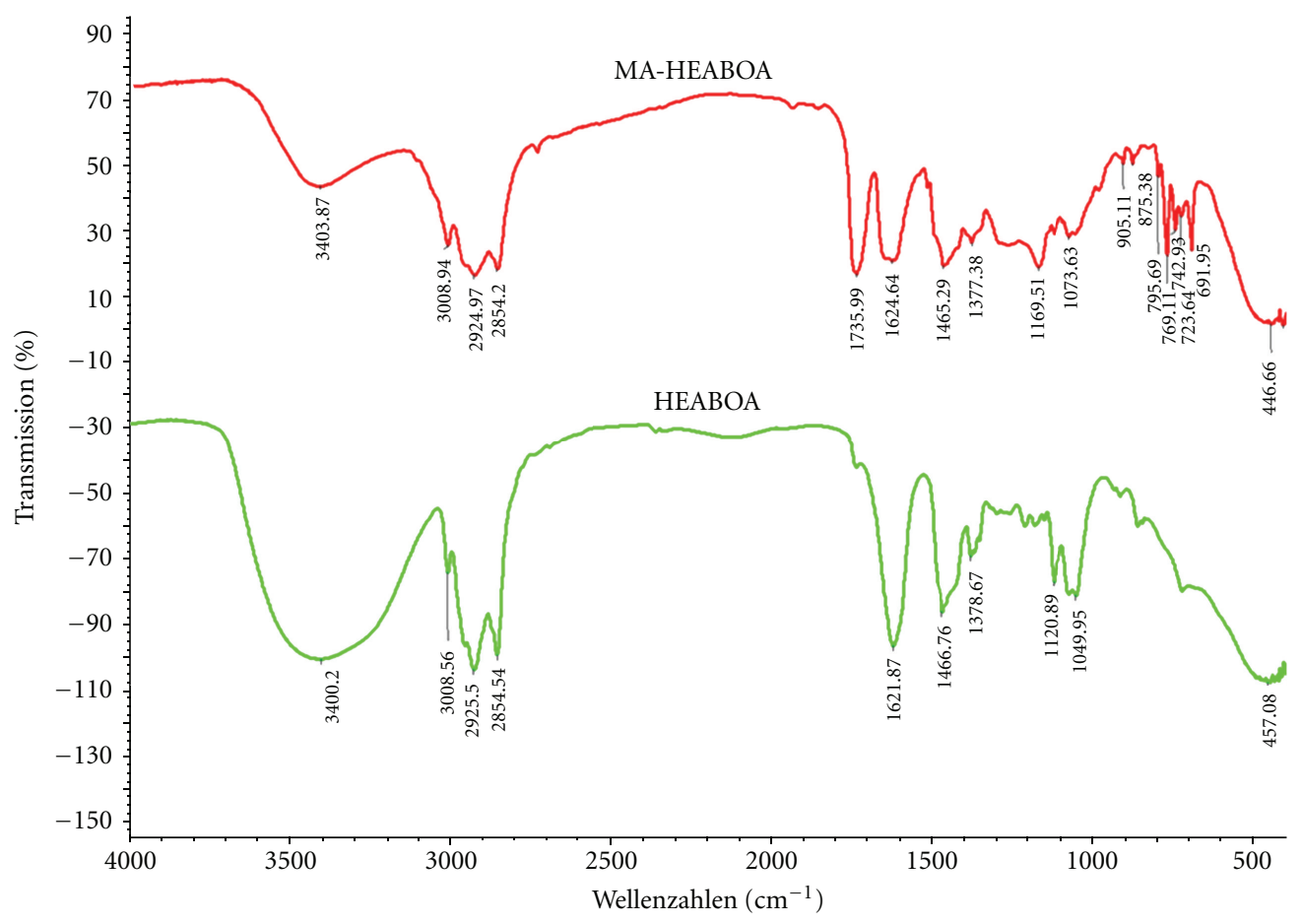

FIgUre 1: FT-IR of HEABOA and MA-HEABOA.

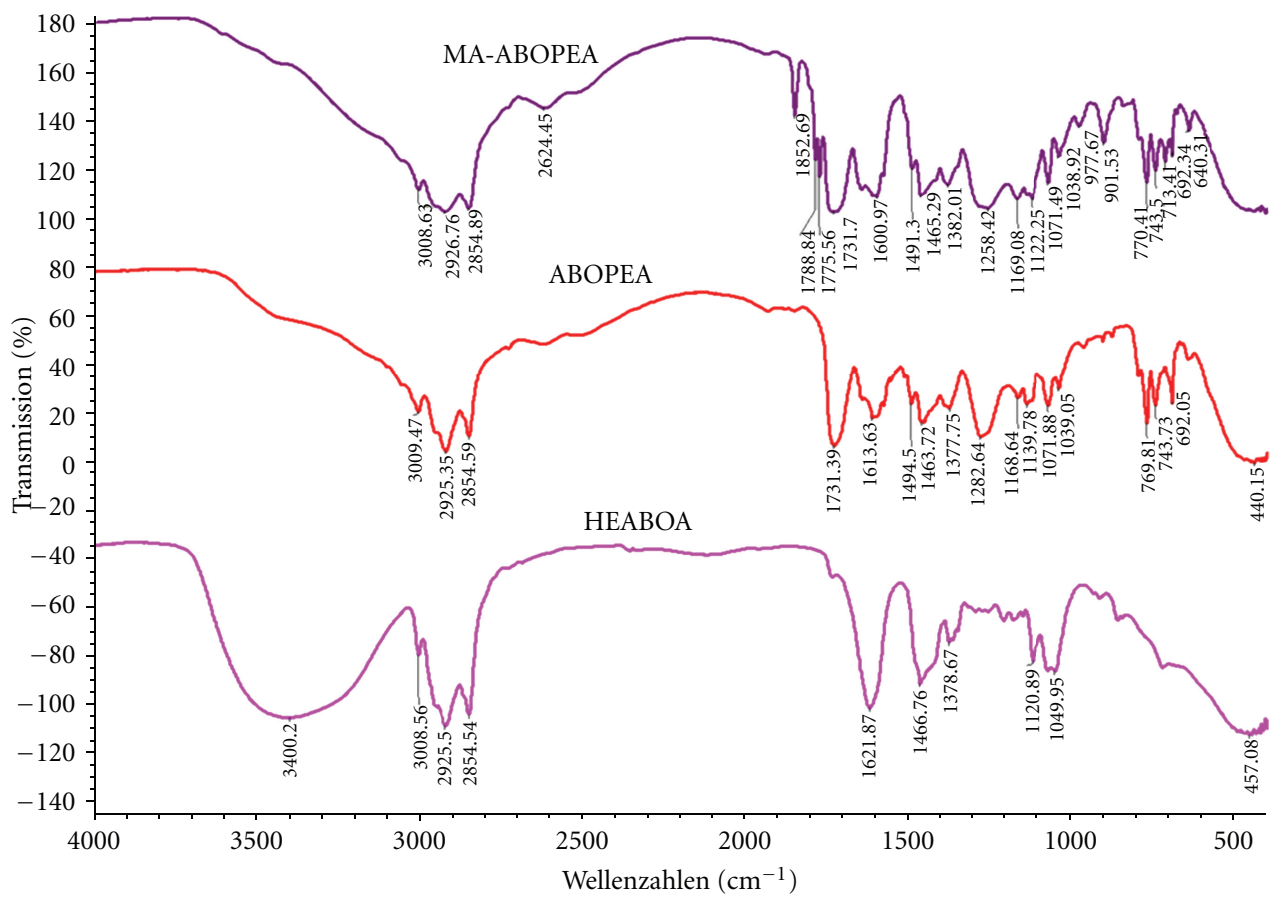

Figure 2: FT-IR of HEABOA, ABOPEA, and MA-ABOPEA.

$1071 \mathrm{~cm}^{-1}$. The absorption bands around 700 to $770 \mathrm{~cm}^{-1}$ are due to the presence of $\mathrm{C}-\mathrm{H}$ vibrations in the phthalic acid ring. There is a small hub around $3437 \mathrm{~cm}^{-1}$ which may be assigned to $\mathrm{OH}$ band. This $\mathrm{OH}$ band is suppressed and the suppression may be due to the presence of one terminal $\mathrm{OH}$ group in a large molecule of the ABOPEA.
The FT-IR of MA-ABOPEA shows appearance of new peaks at $1852,1788-1755 \mathrm{~cm}^{-1}$ which may be ascribed to the carbonyl of phthalic acid moiety as shown in Scheme 3 as well as carbonyl of some residual maleic anhydride. The broad unresolved band at $1600 \mathrm{~cm}^{-1}$ is assigned to aromatic $\mathrm{C}=\mathrm{C}$. The $\mathrm{CH}$ deformation bands at $699-770 \mathrm{~cm}^{-1}$ indicate 


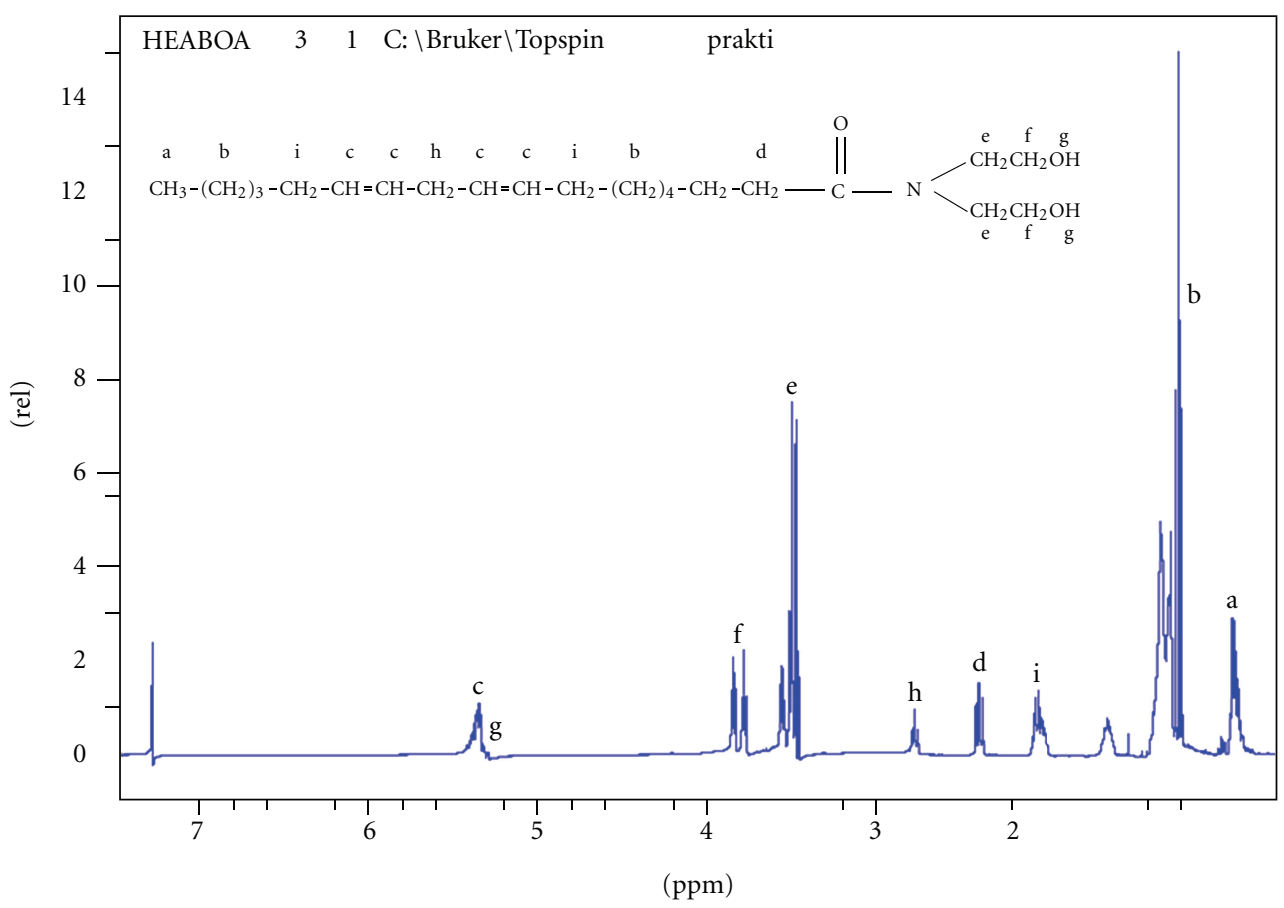

Figure 3: ${ }^{1} \mathrm{H}$ NMR of HEABOA.

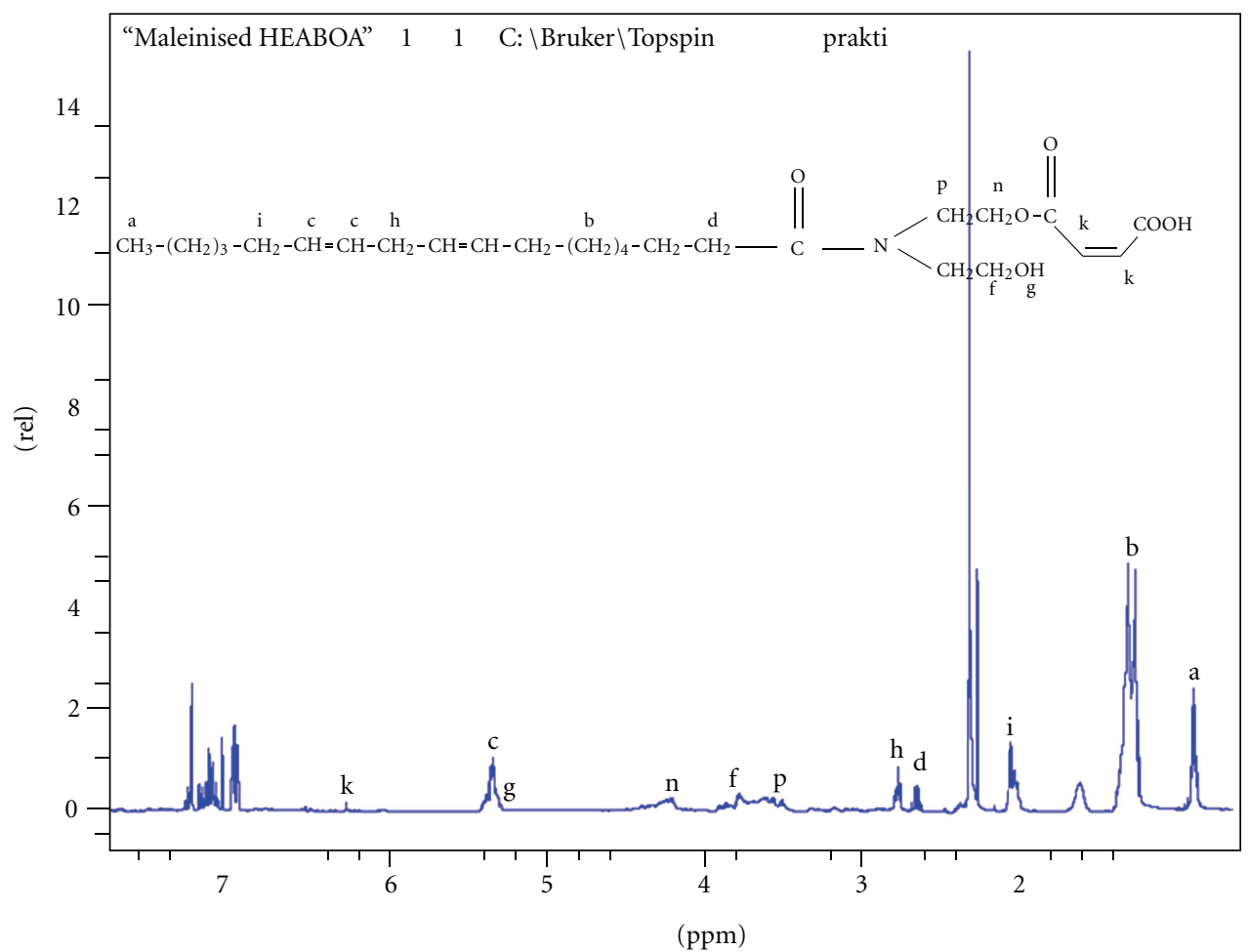

Figure 4: ${ }^{1} \mathrm{H}$ NMR of MA-HEABOA.

the presence of substituted benzene ring. All these corroborate the reaction of phthalic anhydride with MA-HEABOA to form MA-ABOPEA.

${ }^{1}$ HNMR of the HEABOA and MA-HEABOA are presented in Figures 3 and 4, respectively. Figure 3 reveals proton of terminal $\mathrm{CH}_{3}$ at $\delta=0.88$, chain $\mathrm{CH}_{2}$ at $\delta=1.28 \mathrm{ppm}$, $\mathrm{CH}_{2}$ adjacent to $\mathrm{C}=\mathrm{O}$ of amide at $\delta=2.3-2.4 \mathrm{ppm}, \mathrm{CH}_{2}$ sandwiched between two $\mathrm{C}=\mathrm{C}$ at $\delta=2.7-2.8 \mathrm{ppm}, \mathrm{CH}_{2}-\mathrm{OH}$ at $\delta=3.7-3.8 \mathrm{ppm}$, and $\mathrm{OH}$ band overlapped with $\mathrm{C}=\mathrm{C}$ of fatty acid chain at $\delta=5.3-5.4 \mathrm{ppm}$. $\mathrm{CH}_{2}$ adjacent to amide 


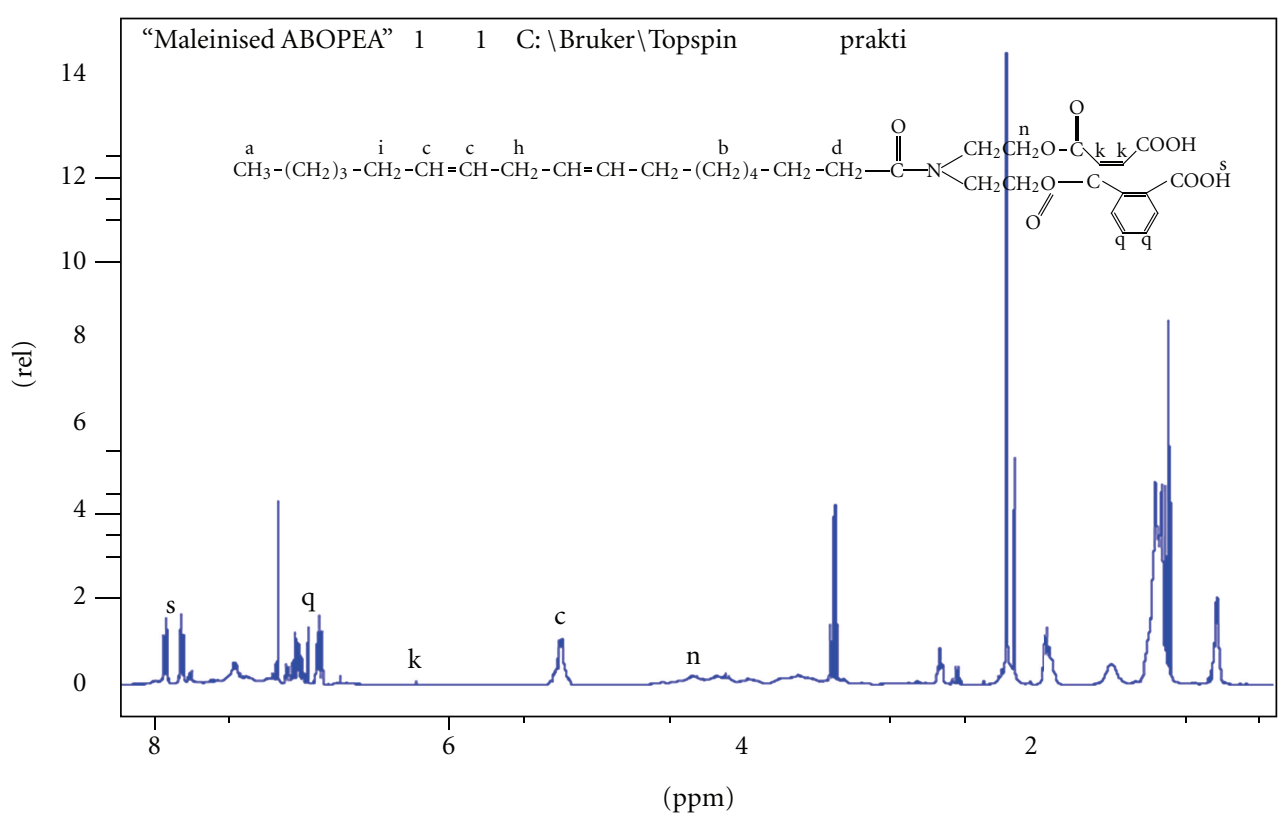

Figure 5: ${ }^{1} \mathrm{H}$ NMR of MA-ABOPEA.

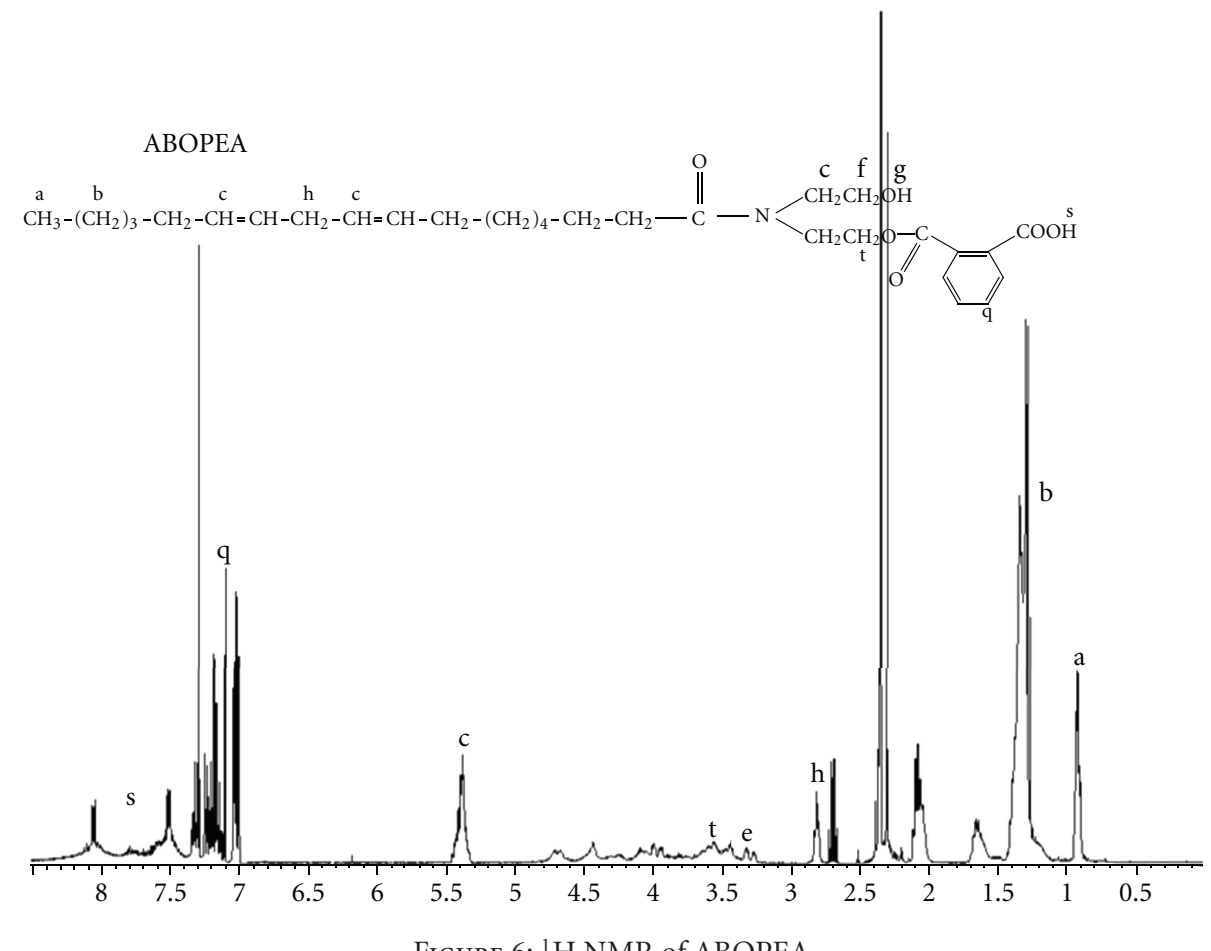

Figure 6: ${ }^{1} \mathrm{H}$ NMR of ABOPEA.

nitrogen appear at $\delta=3.4-3.5 \mathrm{ppm}$. In the ${ }^{1} \mathrm{H}$ NMR of the MA-HEABOA, characteristic peak for $\mathrm{CH}_{2} \mathrm{OH}$ at $\delta=$ $3.7-3.8 \mathrm{ppm}$ reduced considerably and maleate vinyl protons ( $\mathrm{HOOC}-\mathrm{CH}=\mathrm{CH}-\mathrm{COO}-$ ) may be observed at $\delta=6.3 \mathrm{ppm}$ while the methene signals $\mathrm{HOOC}-\mathrm{CH}=\mathrm{CH}-\mathrm{COO}-\mathrm{CH}_{2}$ appear at $\delta=4.2 \mathrm{ppm}$.

The ${ }^{1} \mathrm{H}$ NMR of ABOPEA reveals a singlet peak for terminal $\mathrm{CH}_{3}$ at $\delta=0.92 \mathrm{ppm}$ (Figure 6). The peak at $\delta=1.28 \mathrm{ppm}$ may be assigned to chain $-\mathrm{CH}_{2}$ stretching vibration. Peak at $\delta=2.31 \mathrm{ppm}$ is assigned to $-\mathrm{CH}_{2}$ adjacent to carboxyl group. $\mathrm{CH}_{2}$ sandwiched between two $\mathrm{C}=\mathrm{C}$ appears at $\delta=2.8 \mathrm{ppm}$ and the $-\mathrm{CH}_{2}$ attached to carbonyl of phthalic acid appears at $\delta=6.99-7.28 \mathrm{ppm}$ while carboxylic $\mathrm{OH}$ appears at $\delta=7.49-8.05 \mathrm{ppm}$. Figure 5 is the ${ }^{1} \mathrm{H}$ NMR of the MA-ABOPEA and it reveals the characteristic peaks in the MA-HEABOA, but with disappearance of the $\mathrm{CH}_{2} \mathrm{OH}$ peak at $\delta=3.7-3.8$ and appearance of ring protons at $\delta=$ 6.9-7.2 ppm and carboxylic $\mathrm{OH}$ at $\delta=7.8-8.0$. These spectra analysis support the structures of HEABOA, MA-HEABOA, ABOPEA, and MA-ABOPEA as proposed in Schemes 1-4. 


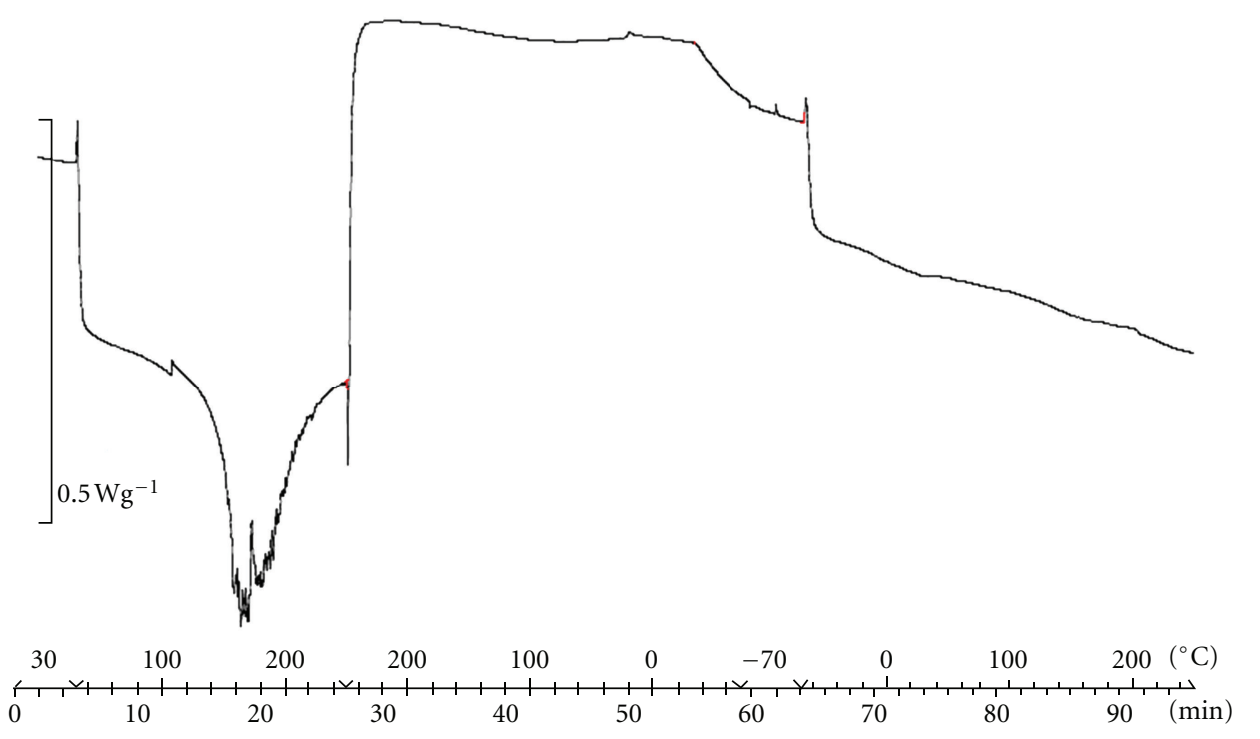

FIGURE 7: DSC thermogram of ABOPEA.

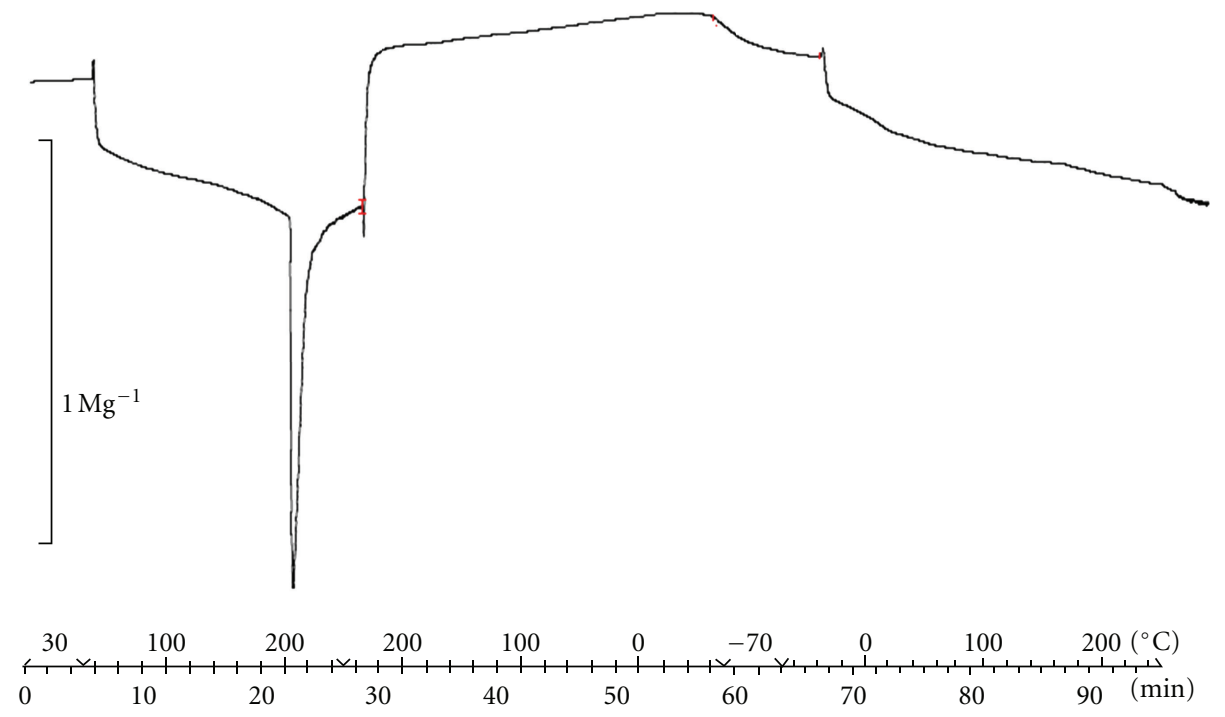

FIgURE 8: DSC thermogram of MA-ABOPEA.

\section{Physicochemical Characteristics}

Table 1 shows the physicochemical characteristics of the samples. The decrease in hydroxyl value (HV) of HEABOA in ABOPEA corroborates the reaction of phthalic anhydride with some hydroxyl groups of the HEABOA to form ABOPEA. In a similar manner, the decrease in HV of MAHEABOA in MA-ABOPEA indicates the reaction of maleic anhydride with $\mathrm{OH}$ of HEABOA to form the half maleate as proposed in Scheme 2 and the much decrease in $\mathrm{HV}$ in MA-ABOPEA corroborates the reaction of the remaining hydroxyl groups in MA-HEABOA with phthalic anhydride to form the MA-HEABOA as proposed in Scheme 3.

Acid value (AV) determination for HEABOA was required to determine whether most fatty acids in the oil reacted with diethanolamine to form the diethanolamide.
The low acid value obtained (0.8) was a good indication of the fact that most of the acid, in form of methyl esters, reacted with diethanolamine. The higher acid value observed for ABOPEA, MA-HEABOA, MA-ABOPEA may be related to the presence of free carboxylic acid in these samples.

The decrease in iodine value (IV) and saponification value (SV) from oil to MA-ABOPEA may be attributed to progressive increase in molar mass and polymeric chain. The higher values of specific gravity (SG) and refractive index (RI) from oil to Ma-ABOPEA may also be related to higher molecular mass of the samples.

\section{Film Properties}

Results of the film properties are presented in Table 2. Drying time of ABOPEA and MA-ABOPEA was recorded at an 
TABLE 1: Fatty acid composition of $\mathrm{ABO}$ and physicochemical characteristics of ABO, HEABOA, MA-HEABOA, ABOPEA, and MAABOPEA.

\begin{tabular}{|c|c|c|c|c|c|}
\hline & $\mathrm{ABO}$ & HEABOA & MA-HEABOA & ABOPEA & MA-ABOPEA \\
\hline Hydroxyl value (mg KOH\g) & 0.30 & 10.52 & 6.75 & 5.25 & 1.52 \\
\hline Iodine value (mg iodine $\backslash \mathrm{g})$ & 104.5 & 85.5 & 90.2 & 60.3 & 82.5 \\
\hline Saponification value $(\mathrm{mg} \mathrm{KOH} \backslash \mathrm{g})$ & 185.30 & 135 & 130 & 128 & 125 \\
\hline Acid value $(\mathrm{mg} \mathrm{KOH} \backslash \mathrm{g})$ & 8.12 & 0.8 & 10.2 & 18.5 & 19.5 \\
\hline Specific gravity $\left(25^{\circ} \mathrm{C}\right)$ & 0.915 & 0.923 & 0.935 & 0.930 & 0.940 \\
\hline Refractive index & 1.4735 & 1.4850 & 1.4925 & 1.4920 & 1.4950 \\
\hline Palmitic (\%) & 14.13 & & & & \\
\hline Stearic $(\%)$ & 11.2 & & & & \\
\hline Oleic (\%) & 20.7 & & & & \\
\hline Linoleic (\%) & 47.9 & & & & \\
\hline Linolenic (\%) & 5.8 & & & & \\
\hline
\end{tabular}

TABle 2: Physicomechanical performance of ABOPEA and MAABOPEA.

\begin{tabular}{lcc}
\hline & ABOPEA & MA-ABOPEA \\
\hline Drying time (min) at $110^{\circ} \mathrm{C}$ & 60 & 35 \\
Impact resistance (g) & 1000 & 1500 \\
Flexibility & Fail & Pass \\
Scratch hardness (Pencil Brand) & $4 \mathrm{~B}$ & $2 \mathrm{H}$ \\
\hline
\end{tabular}

elevated temperature $\left(110^{\circ} \mathrm{C}\right)$ because the samples were non-drying and remained tacky for a long period of time at ambient conditions. Drying time $\left(110^{\circ} \mathrm{C}\right)$ was $60 \mathrm{~min}$ for ABOPEA and $35 \mathrm{~min}$ for MA-ABOPEA. The maleate groups increased the molecular weight as well as introduced more unsaturation in the MA-ABOPEA. With increased unsaturation, crosslinks are easily formed and with increased molecular eight, fewer crosslinks are required to form coherent films and reach the dry stage.

Table 2 shows that MA-ABOPEA showed improved impact resistance over the ABOPEA. This may be explained to be due to the presence of the maleate group in the MAABOPEA. It made the resin to attain a reasonable larger chain length, along with desired crosslink density (due to the presence of higher unsaturation). Consequently, this resulted in a fine and dense structure with improved impact resistance. The MA-ABOPEA has better scratch hardness compared to the ABOPEA. While the ABOPEA failed the flexibility tests, the better flexibility of the MA-ABOPEA may be attributed to the presence of the maleate groups. Generally maleic anhydride is known to promote adhesion [7].

\section{Chemical Resistance}

The results of the anticorrosive properties of ABOPEA and MA-ABOPEA are presented in Table 3. The MA-ABOPEA are far superior to ABOPEA in anticorrosive ability. The MAABOPEA is unaffected in water, xylene, and $\mathrm{NaCl}(3.5 \mathrm{wt})$ for 7 days and slightly loses gloss in $\mathrm{HCl}(2 \mathrm{wt} \%)$ after 7 days, and in $\mathrm{NaOH}(5 \mathrm{wt} \%)$ after $1 \mathrm{hr}$. The ABOPEA coatings
TABLE 3: Chemical resistance performance of ABOPEA and MAABOPEA.

\begin{tabular}{lcc}
\hline & ABOPEA & MA-ABOPEA \\
\hline Water $(7$ days $)$ & $\mathrm{a}$ & $\mathrm{a}$ \\
Xylene $(7$ days $)$ & $\mathrm{b}$ & $\mathrm{a}$ \\
$5 \% \mathrm{NaOH}(1 \mathrm{hr})$ & $\mathrm{e}$ & $\mathrm{b}$ \\
$2 \% \mathrm{HCl}(7$ days $)$ & $\mathrm{c}$ & $\mathrm{b}$ \\
$3.5 \% \mathrm{NaCl}(7$ days $)$ & $\mathrm{b}$ & $\mathrm{a}$ \\
\hline
\end{tabular}

a: Unaffected; b: slight loss in gloss; c: loss in gloss; d: film partially removed; c: film completely removed.

however was completely removed in $\mathrm{NaOH}$ ( $5 \mathrm{wt} \%$ ) after $1 \mathrm{hr}$, loses gloss considerably in $\mathrm{HCl}(2 \mathrm{wt} \%)$ after 7 days and slightly loses gloss in $\mathrm{Nacl}(3.5 \mathrm{wt} \%)$ and xylene after 7 days. The better corrosion resistance of MA-ABOPEA may be attributed to the presence of maleate half esters in them which provide the required degree of crosslinking density that helps in producing a most uniform and well-adhered coating on the surface of the substrate.

\section{Differential Scanning Calorimetry (DSC)}

The curing temperature range of ABOPEA and MAABOPEA was investigated by DSC. Results are presented in Figures 7 and 8. The curing of ABOPEA was found to start at $249^{\circ} \mathrm{C}$ while the curing temperature of Ma-ABOPEA was much lower, $190^{\circ} \mathrm{C}$. The decrease in the initial curing temperature can be attributed to the presence of maleate groups in the MA-ABOPEA which led to enhanced rate of crosslinking.

\section{Acknowledgments}

This work was funded by the International Foundation for Science (IFS) Grant no. F $\backslash 4588$-1 to Akintayo C. O. The authors appreciate the provision of NMR spectroscopic facilities by Prof Thomas Ziegler of the Institute of Organische Chemie, Universitat Tubingen, Tubingen, Germany. 


\section{References}

[1] F. Li, D. W. Marks, R. C. Larock, and J. U. Otaigbe, "Fish oil thermosetting polymers: synthesis, structure, properties and their relationships," Polymer, vol. 41, no. 22, pp. 7925-7939, 2000.

[2] N. Boquillon and C. Fringant, "Polymer networks derived from curing of epoxidised linseed oil: influence of different catalysts and anhydride hardeners," Polymer, vol. 41, no. 24, pp. 8603$8613,2000$.

[3] C. O. Akintayo and K. O. Adebowale, "Synthesis and characterization of acrylated Albizia benth medium oil alkyds," Progress in Organic Coatings, vol. 50, no. 4, pp. 207-212, 2004.

[4] C. O. Akintayo and K. O. Adebowale, "Synthesis, characterization and evaluation of chlorinated Albizia benth medium oil alkyds," Progress in Organic Coatings, vol. 50, no. 2, pp. 138143, 2004.

[5] DFG, German Society for Fat Science, German Standard Methods for the Analysis of Fats and Other Lipids, Wissenschaftliche Verlagsgesellschaft mbH, Stuttgart, Germany, 1994.

[6] Indian Standard Specifications (IS), vol. 158, pp. 8-9, 1981.

[7] B. Trivedi and B. M. Culbertson, Maleic Anhydride, Plenum Press, New York, NY, USA, 1982. 

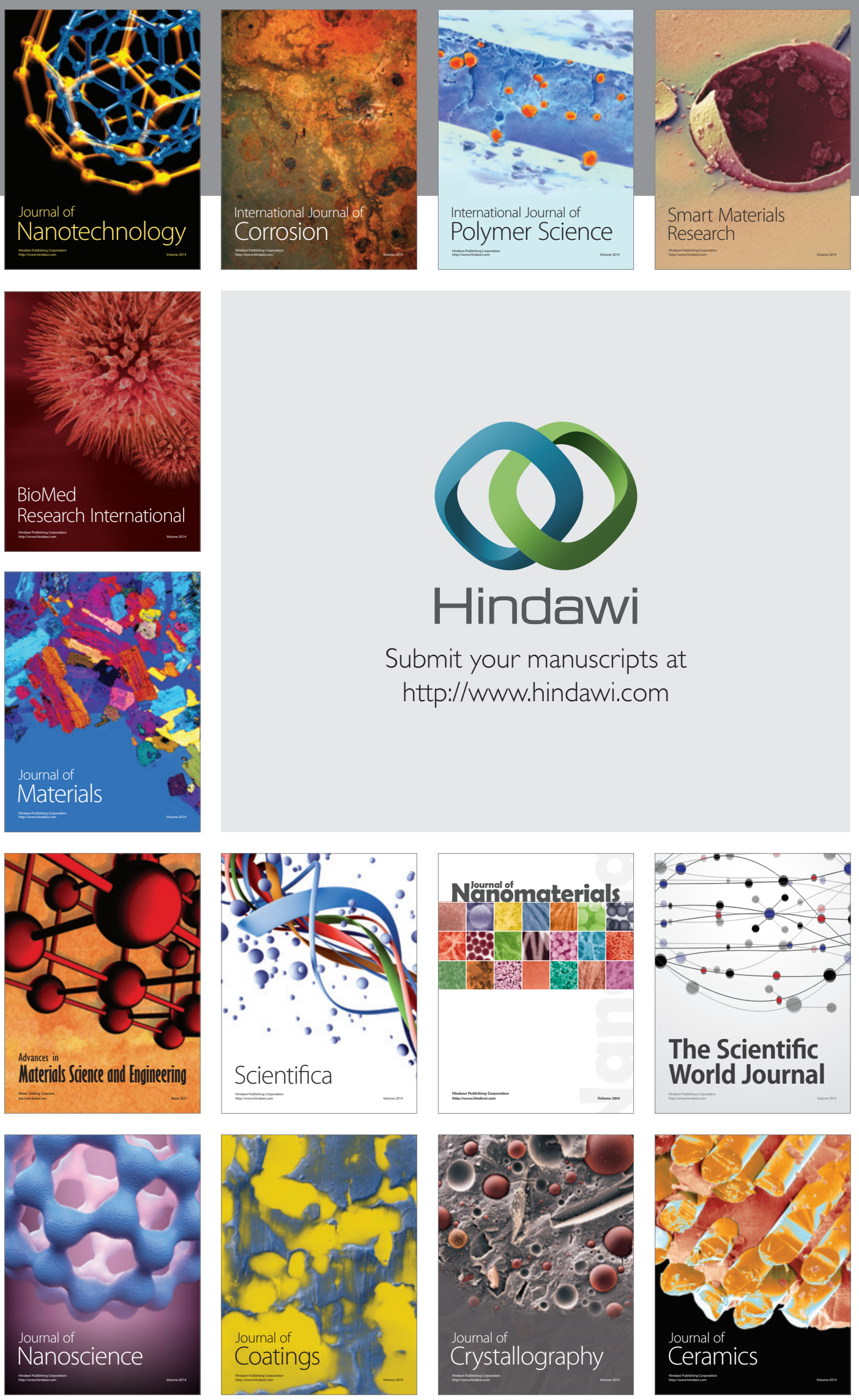

The Scientific World Journal

Submit your manuscripts at

http://www.hindawi.com

\section{World Journal}

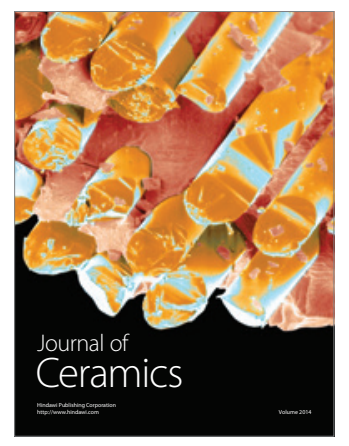

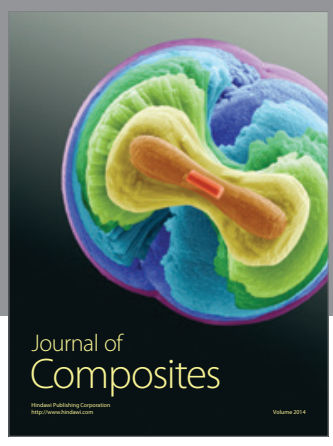
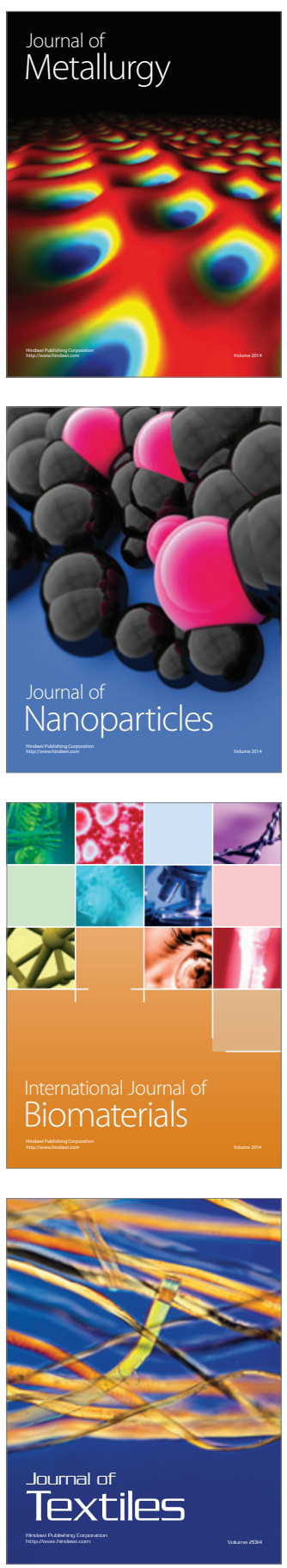